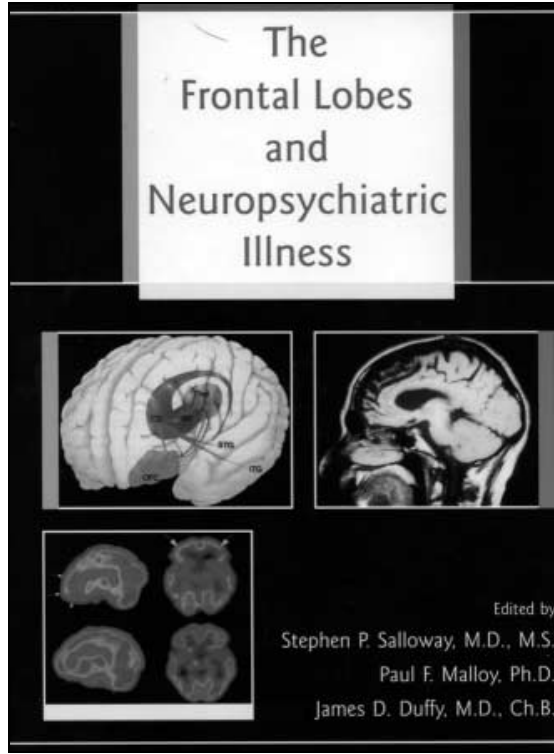

role of the frontal cortex is the next topic of discussion. This is followed by two chapters on the neuropsychological aspects of frontal lobe function, in particular examining laterality issues and the role of the frontal lobes for consciousness and self-awareness.

The next main section deals with the more classically described prefrontal syndromes found in clinical practice (a dorsal convexity syndrome, an orbitofrontal syndrome and a medial frontal syndrome), with chapters devoted to description, diagnosis, assessment and management. A disappointment with the latter is the sparsity of studies, particularly of psychopharmacological treatments, and the lack of very effective remedies. Anger management, with targeted cognitive-behavioural therapy, unfortunately is not discussed.

The final part of the text concentrates on frontal lobe dysfunction in various psychiatric disorders, depression and schizophrenia representing the main topics. However, the important area of traumatic brain injury and more recondite disorders such as reduplicative paramnesia and the Capgras and Othello syndromes and other content-specific delusions, are also included.

The last chapter returns to an old theme, the neurosurgical treatment of refractory obsessive-compulsive disorder using interventions that interrupt frontosubcortical connections. The chief author of this chapter is the late Per Mindus, who was actively involved in this exciting area of research before his death in 1998 and to whom the book is appropriately dedicated.
If you want a good all-round, comprehensive, readable update on the frontal lobes in relationship to neuropsychiatric disorder, then this is the text for you.

Michael R. Trimble Professor in Behavioural Neurology and Consultant Physician in Psychological Medicine, National Hospital for Neurology and Neurosurgery, Queen Square, London WCIN 3BG, UK

\section{Geriatric Consultation Liaison Psychiatry}

Edited by Pamela Melding \& Brian Draper Oxford: Oxford University Press. 2001. 396 pp. $€ 32.50$ (pb). ISBN 0192630849

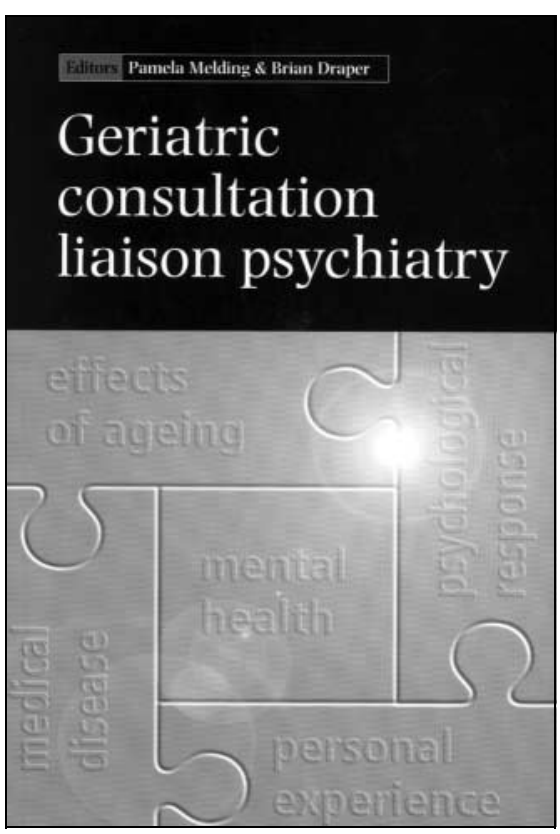

This welcome book brings together knowledge pertinent to the care of older patients with mental health problems in a general hospital setting. It acknowledges that the needs of such patients are to some extent different and often more complex than those of younger patients.

The book is clearly and concisely written, from an international perspective, reminding us of the similar challenges faced by clinicians in different countries. A holistic view is emphasised throughout. Each chapter is clinically oriented, with numerous case vignettes to illustrate points made, reminiscent of patients we have all encountered.

The text is organised into five sections. The first covers the context of the geriatric consultation liaison referral, including a discussion of service organisation and of the implications of the ageing process and of pyschosocial issues. The section on assessment is comprehensive and draws attention to the particular difficulties encountered in liaison settings. The reader is reminded that liaison is a 'very time-consuming pursuit'. Specific disorders, as they present in a general hospital context, are discussed in some detail, including an excellent chapter on the more challenging 'undesirable' patients encountered together with approaches to understanding and managing their problems. The section on treatment includes psychopharmacological and non-biological treatments as well as a review of electroconvulsive therapy in older patients with physical illness. The final section includes a helpful and thought-provoking discussion of ethical and legal issues that arise in this patient group. There is a glossary of terminology and a comprehensive index that facilitates the book's use for reference purposes.

For a clear exposition of the complexities associated with the assessment of older people in hospital, the interactions between psychiatric and physical disorder, the effects of ageing and the influence of personal experience on how people cope with disease, together with a very practical overview of treatment and management options available, this book can be firmly recommended. It will be of value to all old age psychiatrists, liaison psychiatrists and geriatricians and a source of guidance to trainee psychiatrists venturing onto medical wards for the first time. It will also be of interest to primary care physicians, as many of the issues discussed apply similarly in community settings.

Deborah M. Girling Consultant in Old Age Psychiatry, Addenbrooke's NHS Trust, Fullbourn Hospital, Cambridge CBI 5EF, UK

\section{Personality Disorder and Human Worth: Papers from a Conference Organised by the Board for Social Responsibility}

Edited by the Board for Social Responsibility. London: The Church of England. 200I. 43 pp. $£ 3.00(\mathrm{pb})$. No ISBN

Although most psychiatrists have heard of Michel Foucault, I suspect that they do not 
spend much time worrying about the proper limits of medical power. It is easy to ignore ideas expressed in a manner that is obscure even by the standards of French intellectuals. In any case, the experience of working in the National Health Service soon reduces one's ability to empathise with a man who worries about doctors taking over the world.

Although psychiatrists may not worry about medical power, medical responsibility is a different matter, and they have been learning a lot about it in recent years. In this context, dangerous severe personality disorder (DSPD) is 'Foucault's revenge'. Doctors have been attaching stigmatising labels to difficult people for years and they will now be forced to treat them (with discipline and punishment for doctor and patient alike, if things go wrong).

Critics of the DSPD initiative emphasise the problem of 'medicalisation'. They fear that psychiatric concepts are being extended into areas of life where other models, whether moral or criminological, are more appropriate. As a contribution to this debate, one must welcome a publication from the Church of England's Board for Social Responsibility. Is this the Church's big fightback, a crusade to reclaim moral territory from the medical infidel? The title, with its reference to human worth, promises a critique of reductionism. We look forward to an alternative to the scientific view of human problems as technical difficulties to be solved by experts.

These expectations are dampened by the realisation that the first two contributors are psychiatrists, a disappointment offset by the fact that there is little psychiatry in their papers. Professor Nigel Eastman summarises the ethical objections to the proposed new Mental Health Act and Dr Bob Johnson reminds us that many violent offenders had terrible childhoods. Next the Governor of Grendon Prison summarises that institution's approach to therapy, and Jonathan Sedgewick (then Head of the DSPD programme at the Home Office) sets out proposals for the shape of services for people with DSPD. It is only in the fifth and final paper that one comes to 'a theologian's questions', addressed by Professor Nicolas Sagovsky, a specialist in Christian social ethics.

The most surprising thing about the theologian's questions is the extent to which they resemble those asked by the other contributors. They raise concerns about the precision of risk assessment and about the proper balance between the rights of the individual and of society. Despite the references to God, one is left with the feeling that there is little to distinguish religious and humanistic ideas in this field.

This pamphlet is inexpensive and provides a good introduction to the area for anyone who is new to it. Many psychiatrists will be familiar with the arguments and there are no new ethical insights. I was disappointed by the avoidance of some difficult questions. Contributors point out that, if we detain people on the basis of risk, the nature of probability is that we lock up people who would not have committed an offence together with those who would have. This fact is presented as though it precludes the detention of those whose personality disorder is associated with a high risk of violence. None of the contributors goes on to ask how psychiatry can justify detaining people with mental illness, to whom the same laws of probability apply. Foucault would have asked this question, and it deserves an answer.

I may have been unfair in failing to identify a distinctive religious element in this publication. As I wrote the review, the morning's news was dominated by a fierce row about whether or not a confused 94-year-old woman had made a racist remark that could justify her neglect during a 3-day stay in a casualty department. Medical staff pitched into the fray, as if dignity and confidentiality were going out of fashion. The theologian's paper includes an optimistic call for informed debate and responsibility in political life. The difference is faith.

Anthony Maden Professor of Forensic Psychiatry, Imperial College of Science, Technology and Medicine, Academic Centre, Trust Headquarters, West London Mental Health NHS Trust, Uxbridge Road, Southall, Middlesex UBI 3EU, UK

\section{A War of Nerves: Soldiers and Psychiatrists}

By Ben Shephard. London: Jonathan Cape. 2000.487 pp. $€ 20.00$ (hb).

ISBN 0224060333

This is a timely publication. Military psychiatry is currently in the spotlight, owing to the recent commencement of a class action in the High Court alleging that the British military medical services failed in their duty of care to prevent trauma and then adequately treat individuals traumatised by war. Ben Shephard has extensively researched this area and provides a comprehensive account of the development of military psychiatry. One of the themes of this book is how combatrelated psychiatric disorder is inextricably linked with political, social and cultural issues. He also illustrates how the history of military psychiatry is closely associated with many of the most fundamental ideas in psychiatry.

The author is a historian who has contributed to a number of television series. He gives a comprehensive and authoritative account, which is at the same time an excellent read. Most impressively, as well as getting the military history correct, he writes with what appears to be an excellent understanding of psychiatric and medical issues. The book begins with the origins of shell-shock and the struggle between the ideas of Mott, Meyer and others leading up to the report of the 1922 Committee on Shell-Shock. This subject has been covered in many other works, but few are as balanced and detailed as this. More interesting, perhaps, is that Shephard continues with less-reported periods in the later part of the 20th century, including the Second World War, the Korean War, Vietnam and modern conflicts such as the Falklands. He manages to examine the development of ideas in the

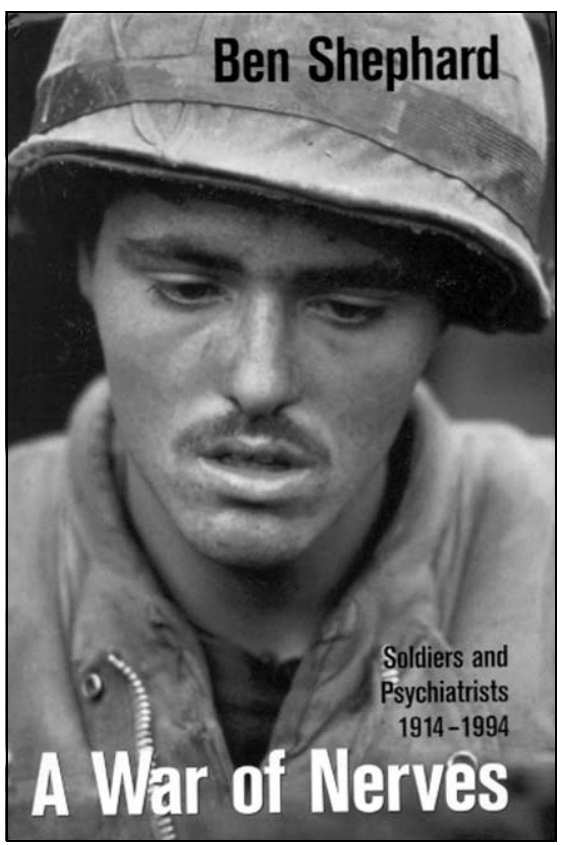

